\title{
Rapid change of tundra snow hardness in Alaska
}

\author{
Konosuke SUGIURA, ${ }^{1,2}$ Daqing YANG, ${ }^{3}$ Tetsuo OHATA ${ }^{1}$ \\ 1Japan Agency for Marine-Earth Science and Technology, Research Institute for Global Change, Yokosuka 237-0061, Japan \\ E-mail: sugiura@jamstec.go.jp \\ ${ }^{2}$ International Arctic Research Center, University of Alaska Fairbanks, 930 Koyukuk Drive, Fairbanks, AK 99775-7340, USA \\ ${ }^{3}$ Water and Environmental Research Center, Institute of Northern Engineering, 306 Tanana Drive, \\ University of Alaska Fairbanks, Fairbanks, AK 99775-5860, USA
}

\begin{abstract}
To understand the formation of hard snow in the field and its relationship to the physical parameters of snow surfaces, we carried out snowpack observations at a flat and snow-covered field in Barrow, Alaska. These observations were performed in the middle of winter and included two drifting snow events. After the end of each drifting snow event, the minimum snow surface density increased slightly with time and there was a rapid increase in the minimum snow surface hardness. There was no rain during our observations. Therefore, the strong bonds among the snow surface particles were not due to melting and refreezing; they formed because of hardening during water-vapor transport under a temperature gradient and also by exposure of the inner snow layer through erosion. As a consequence, the snow formed a hard surface following the drifting snow events.
\end{abstract}

\section{INTRODUCTION}

It is widely recognized that snow cover plays an important role in energy exchange between the bottom of the atmospheric boundary layer and the top of the Earth's surface. The state of an upper snow layer is dynamic because new snow layers form as a result of snowfall and old snow layers are exposed as a result of erosion due to drifting snow. Although various researchers have reported hard snow in mountainous areas (e.g. Martinelli, 1971; Aburakawa and others, 1972), the natural conditions of hard snow formation in a series of drifting snow events are unclear. However, experimental and modeling studies on snow metamorphism and increased bond strength have steadily accumulated (e.g. Sommerfeld and LaChapelle, 1970; Colbeck 1987; Gray and Morland, 1995). To better understand hard snow formation in snow surface layers in a series of drifting snow events and its relationship to the physical parameters of snow surfaces, we carried out snowpack observations at a flat, snowy and severely cold field in Barrow, Alaska. These observations were conducted in the middle of winter and included two drifting snow events.

\section{AREA DESCRIPTION, METHODS AND MATERIALS}

We carried out snowpack observations at a flat, snowy field in Barrow (Fig. 1) from 21 February to 5 March 2004. The observation area, of $\sim 200 \times 200 \mathrm{~m}^{2}$, is located on the north side of the Barrow Observatory of the US National Oceanic and Atmospheric Administration (NOAA) at $71.3230^{\circ} \mathrm{N}, 156.6114^{\circ} \mathrm{W}$. The snow cover in this area during the winter is wind-packed, dry and sastrugi-sculpted (Benson and Sturm, 1993). During drifting snow events, deposition and erosion areas were found to occur at the observation site. In addition, the hard snow layer, which is a part of the snowpack, was exposed in the erosion areas. The part of the snowpack with the very hard snow layer appeared after the end of the drifting snow events. However, we excluded it from our snowpack observations because it did not reach a uniform thickness of $>5 \mathrm{~cm}$ and/or was beyond the measurement limit of snow hardness. Snowpack observation points for each day were not spaced equidistantly in the observation area; instead they were selected according to the type of snow surface.

Snow density was measured using a cylindrical snowdensity sampler (inside diameter $29 \mathrm{~mm}$, full length $49 \mathrm{~mm}$ ). For measurements, we dug into the snow and selected points that were uniform over at least a $5 \mathrm{~cm}$ depth from the snow surface. This was done because the values of density and hardness measured at the snow surface layer would be skewed if the layer was not uniform. The sampler was inserted into the uppermost snow surface layer horizontal to the snow surface after digging a small trench. The snow mass was measured using a digital scale and was divided by the volume of the sampler. Using this method, the snow density at each point was obtained.

At the same time, the snow surface hardness was measured using a push-pull gauge (MODEL-9520; Aikoh Engineering). An attachment, $14 \mathrm{~mm}$ in diameter and $5 \mathrm{~mm}$ thick, was mounted on the gauge. The measurement range of the gauge with the attachment was $0-1.3 \mathrm{MPa}$. The gauge was placed vertical to the snow surface at the same observation point as used for the density measurements, and slowly pushed at a constant speed $\left(\mathrm{a}\right.$ few $\mathrm{cm} \mathrm{s}^{-1}$ ) until it was inserted $5 \mathrm{~mm}$ below the snow surface. We repeated measurements five times at each point. The maximum and minimum measurements were excluded, and the arithmetical mean was obtained. Takeuchi and others (2001) confirmed that this push-pull gauge could be used as a snow-hardness meter and was comparable to rammsondeand Kinosita-type hardness meters. Our results show that hardness was correlated with the resistance in terms of the fracture and plastic compression of the snow layer structure.

To monitor drifting snow and meteorological elements at the site, we set up an automatic weather station and a snowparticle counter (SPC) to measure the number of particles $\mathrm{s}^{-1}$ per unit area without capturing them directly (SPC-S7 Special Version; Niigata Electric). The SPC had optical sensors and has previously been shown to obtain valid measurements in field and wind-tunnel observations (Sato and others, 1993; Sugiura and others, 1998). Snow surface temperature was measured using a temperature data logger 


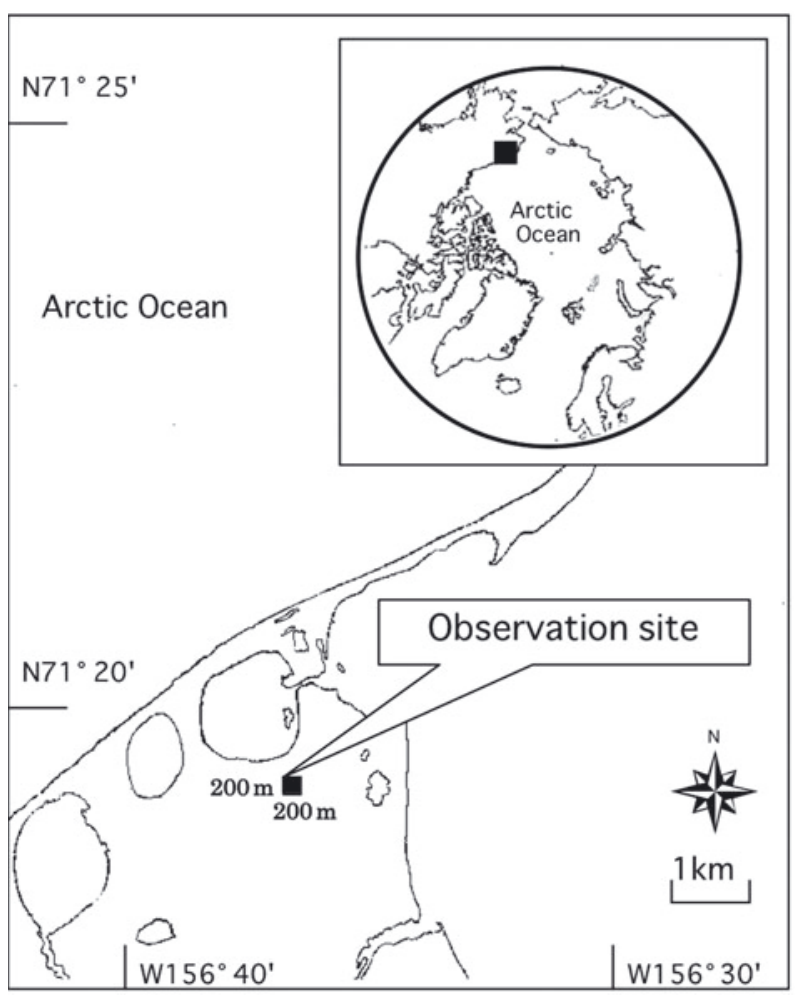

Fig. 1. Map of the observation site.

using a three-wired platinum resistance-type sensor (TR-81; T\&D). The grain size of the snow surface was measured by visual observation, using a loupe and a snow gauge, and photomicrographs were taken of the snow particles mounted on a glass slide.

\section{RESULTS AND ANALYSES}

The data for stationary measurements by the SPC, the windspeed sensor and the air-temperature sensor at the site are shown in Figure 2. During drifting snow events, the snow particles at the snow surface collided with, and rebounded from, the snow surface, occasionally colliding with other particles. Continuous drifting snow with a mass flux of $\sim 1 \times 10^{-5} \mathrm{~kg} \mathrm{~m}^{-2} \mathrm{~s}^{-1}$ is shown as an example in Figure 2a. The wind was strong from 21 to 23 February and from 2 to 3 March and the air temperature decreased on 24 February and 3 March, as shown in Figure $2 b$ and c.

The wind was very weak, and no drifting snow events occurred. These conditions remained for a few days until 20 February. The snowfield was flat, but different types of snow surfaces due to erosion and deposition, such as sastrugi and dune, with height differences of $\sim 50 \mathrm{~cm}$, were formed in patches at the observation site because of previous drifting snow. Approximately $1-2 \mathrm{~cm}$ of fresh snow accumulated and surface hoar grew on the snow surface. As a result, the uppermost snow surface layer was non-uniform to $5 \mathrm{~cm}$ depth.

From 21 to 23 February, the wind was strong (averaging $7.4,8.3$ and $7.8 \mathrm{~m} \mathrm{~s}^{-1}$ on 21,22 and 23 February, respectively), the air temperature increased (averaging $-31.2,-30.8$ and $-28.6^{\circ} \mathrm{C}$ on 21,22 and 23 February, respectively), the sky was clear and drifting snow occurred continuously. From 24 to 25 February, the wind was a breeze (averaging 5.1 and $3.6 \mathrm{~m} \mathrm{~s}^{-1}$ on 24 and 25 February, respectively), the air
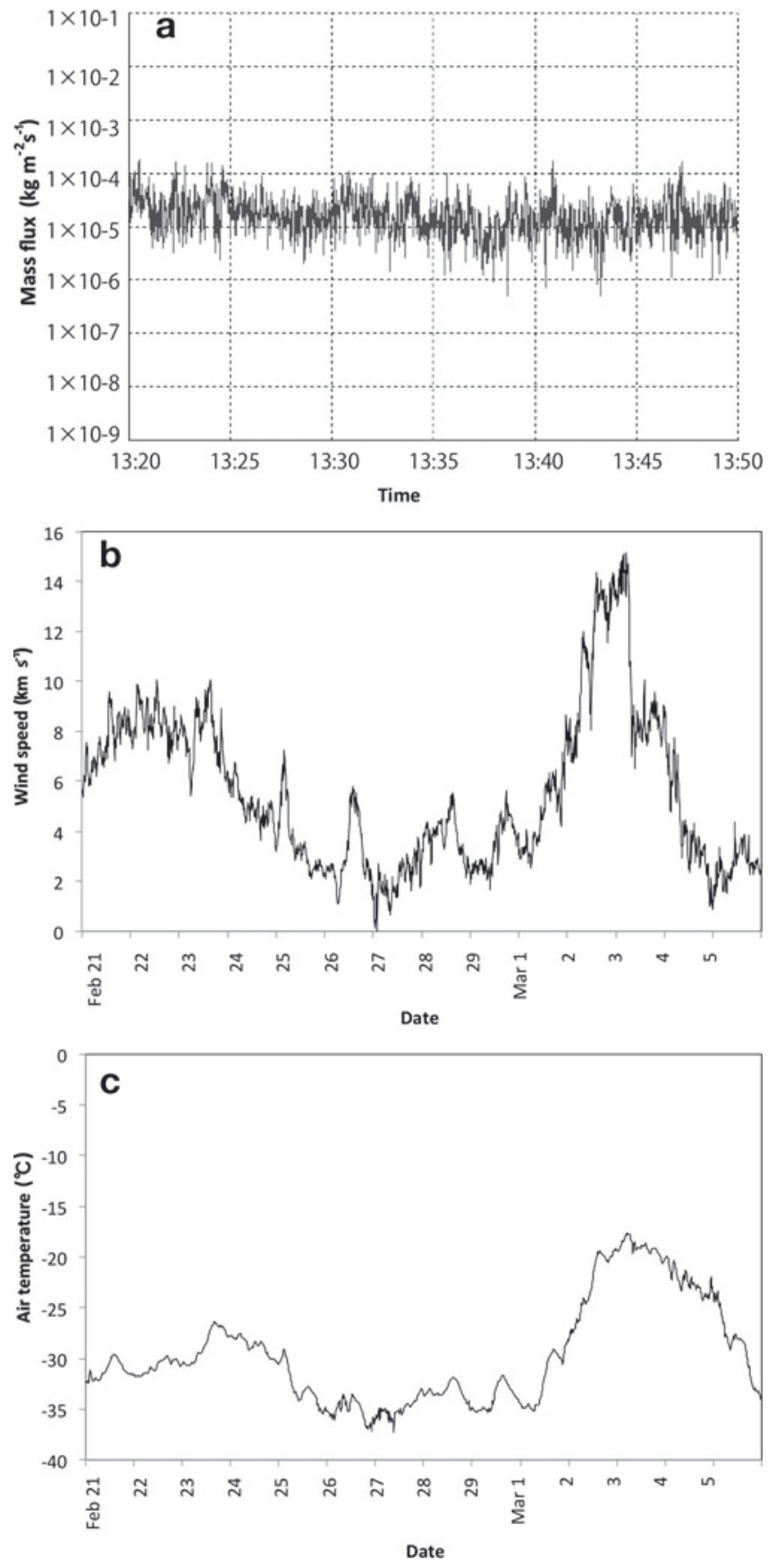

Fig. 2. Meteorological conditions at the site. (a) Mass flux from 13:20 to 13:50 on 21 February 2004. (b, c) Wind speed (b) and air temperature (c) $3 \mathrm{~m}$ above the ground from 21 February to 5 March 2004.

temperature decreased (averaging -28.8 and $-32.9^{\circ} \mathrm{C}$ on 24 and 25 February, respectively), the sky was clear and drifting snow did not occur. After 26 February the surface hoar began to grow. Because of these conditions, the uppermost $5 \mathrm{~cm}$ of the snow surface layer was not uniform after 26 February, so measurements were stopped.

From 2 to 3 March, the wind was strong (averaging 11.1 and $10.0 \mathrm{~m} \mathrm{~s}^{-1}$ on 2 and 3 March, respectively), the air temperature increased (averaging -22.7 and $-19.1^{\circ} \mathrm{C}$ on 2 and 3 March, respectively), the sky was clear and drifting snow occurred continuously. From 4 to 5 March, the drifting snow stopped (wind speed and temperature averaging $4.2 \mathrm{~m} \mathrm{~s}^{-1}$ and $-22.4^{\circ} \mathrm{C}$ on 4 March and $2.6 \mathrm{~m} \mathrm{~s}^{-1}$ and $-28.8^{\circ} \mathrm{C}$ on 5 March). 


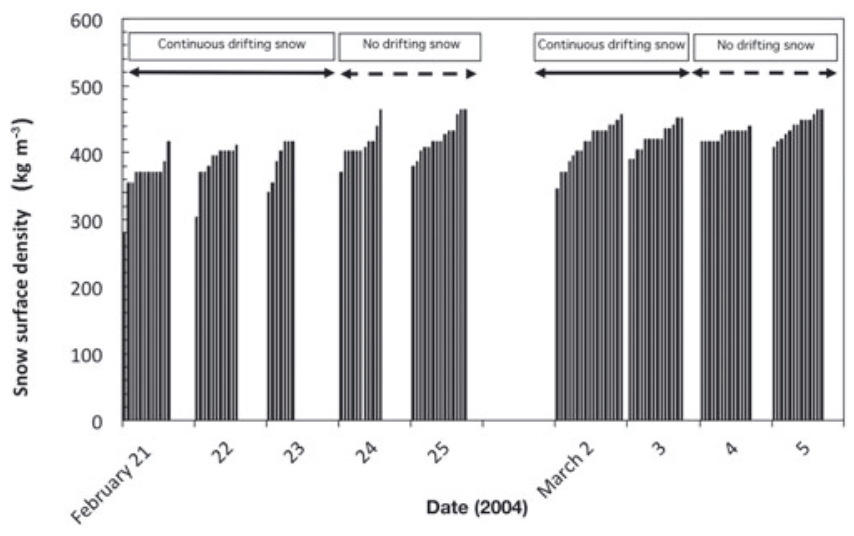

Fig. 3. Snow surface density at the different observation points.

The density, hardness and temperature of the snow surface from 21 to 25 February and 2 to 5 March are shown in Figures 3, 4 and 5, respectively. It was found that the density and hardness of the snow surface varied at all observation points, not because of inaccurate measurements but because of differences in the state of the snow surface. The minimum snow surface density during drifting snow on 21-23 February was $278 \mathrm{~kg} \mathrm{~m}^{-3}$. After the drifting snow event, the snow density increased slightly to $371 \mathrm{~kg} \mathrm{~m}^{-3}$ on 24 February and to $380 \mathrm{~kg} \mathrm{~m}^{-3}$ on 25 February. The same trend was found on 2 and 4 March.

Although there was only a slight change in density, there were significant changes in the minimum snow surface hardness following snow drifting. During the drifting snow event of 21-23 February, minimum snow surface hardness was $5 \mathrm{kPa}$, and it varied widely between a soft value of $5 \mathrm{kPa}$ and a hard value of $>200 \mathrm{kPa}$. After the drifting snow event, on 24 February, the minimum hardness increased to $148 \mathrm{kPa}$ and the maximum hardness increased to $\sim 700 \mathrm{kPa}$. A hard, compacted snow surface also appeared during this time. As shown in Figures 3 and 4, the minimum snow surface hardness changed much more rapidly than the snow surface density. Figure 5 clearly shows a sharp decrease in surface temperature following both drifting snow events.

The grain size is given in Table 1, and Figure 6 shows photographs of snow particles at the different observation points.

The grain size at the observation points in Table 1 ranged from 0.2 to $0.5 \mathrm{~mm}$, irrespective of the occurrence of drifting snow. The six classes used by The International Classification for Seasonal Snow on the Ground (Fierz and others, $2009)$ are: very fine $(<0.2 \mathrm{~mm})$, fine $(0.2-0.5 \mathrm{~mm})$, medium $(0.5-1.0 \mathrm{~mm})$, coarse $(1.0-2.0 \mathrm{~mm})$, very coarse $(2.0$ $5.0 \mathrm{~mm})$ and extreme $(>5.0 \mathrm{~mm})$. Although natural snow hardness is strongly dependent on snow density, temperature and structure, irrespective of the occurrence of drifting snow, the types of snow particle we observed were all similar, as shown in Table 1 and Figure 6. Given that the snow particles

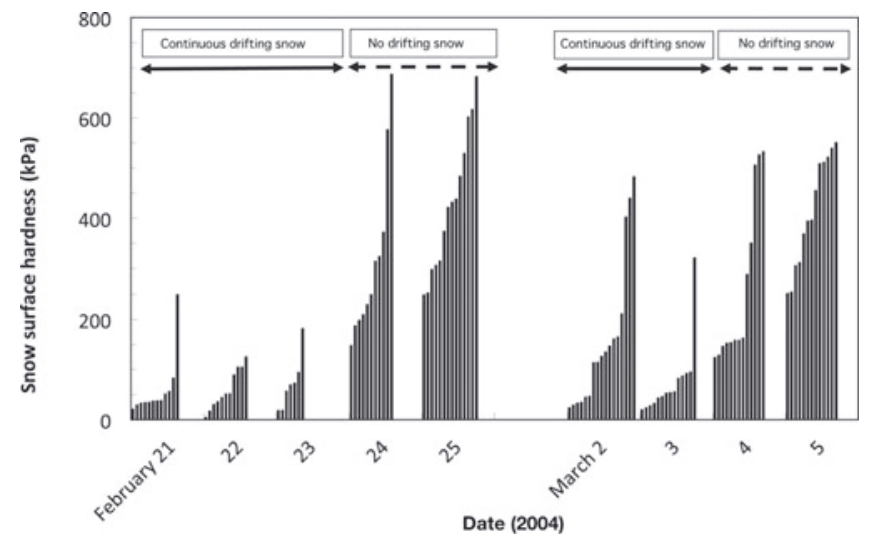

Fig. 4. Snow surface hardness at the different observation points.

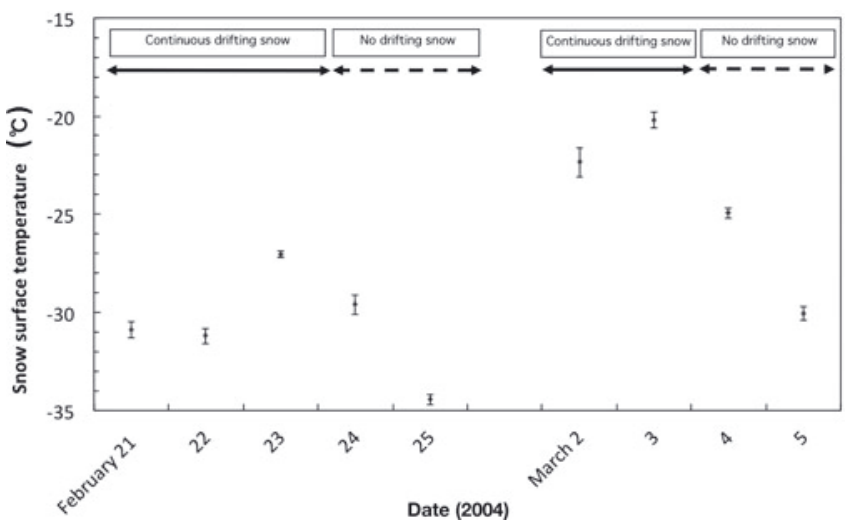

Fig. 5. Snow surface temperature at the different observation points. The bars represent maximum and minimum snow surface temperatures, and circles represent the means.

were scratched from the snow surface layer using a brush, how the bond thickness between the particles developed with time is unclear from this photograph.

\section{DISCUSSION AND CONCLUSIONS}

Kobayashi (1978) carried out cold room experiments on the hardness of artificially compacted snow with long annealing durations at temperatures of $-2,-6,-11,-21$ and $-29^{\circ} \mathrm{C}$. The snow hardness showed a remarkably rapid initial increase at all temperatures, especially at lower temperatures. In addition, based on photomicrograph observations, the bonds between the compacted snow particles became stronger with time. Akitaya (1985) carried out field experiments on the increase of snow hardness under strong temperature gradients at Fraser Experimental Forest, Colorado, USA. In his field experiment, the increase in hardness was most affected by the temperature gradient, followed by snow

Table 1. Grain size at the observation points at the site

\begin{tabular}{|c|c|c|c|c|c|c|c|c|c|}
\hline & 21 Feb. & 22 Feb. & 23 Feb. & 24 Feb. & 25 Feb. & 2 Mar. & 3 Mar. & 4 Mar. & 5 Mar. \\
\hline Diameter (mm) & $0.2-0.5$ & $0.2-0.5$ & $0.2-0.5$ & $0.2-0.5$ & $0.2-0.5$ & $0.2-0.5$ & $0.2-0.5$ & $0.2-0.5$ & $0.2-0.5$ \\
\hline
\end{tabular}



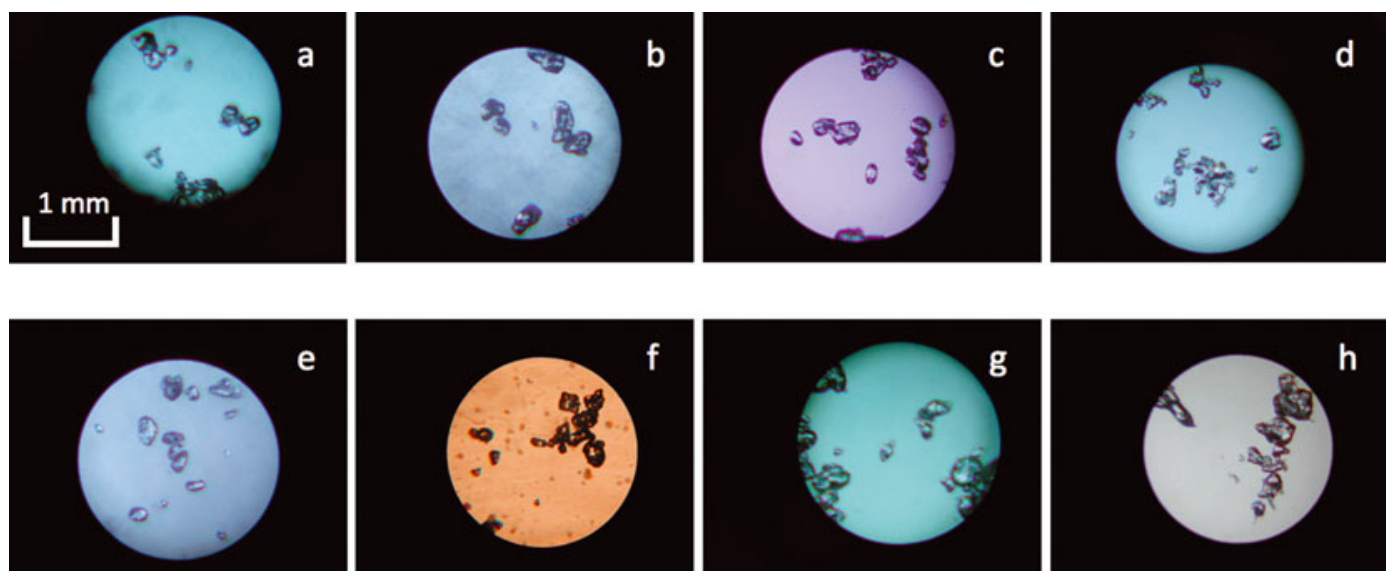

Fig. 6. Conditions of snow particles at the observation points. (a) 22 February, (b) 23 February, (c) 24 February, (d) 25 February, (e) 2 March, (f) 3 March, (g) 4 March and (h) 5 March 2004.

density and snow temperature. In addition, based on photomicrograph observations in a cold room, it was confirmed that connected ice particles were arranged in the direction of the temperature gradient and that bonds between particles of the same temperature grew slowly over time by sintering. When the experimental equation obtained by Akitaya (1985) is converted to SI units, it is given as $\Delta H=$ $1.188 \times 10^{-17}\left|T_{\mathrm{g}}\right|^{1.360} \rho^{4.278}\left|T_{\mathrm{s}}-273.15\right|^{-0.935}$, where $\Delta H$ is the increase in snow hardness after 6 hours $(\mathrm{Pa}), T_{\mathrm{g}}$ is the snow temperature gradient $\left(\mathrm{K} \mathrm{m}^{-1}\right), \rho$ is the snow density $\left(\mathrm{kg} \mathrm{m}^{-3}\right)$ and $T_{\mathrm{s}}$ is the mean snow temperature $(\mathrm{K})$. Figure 7 shows the relation between $\Delta H$ and $T_{\mathrm{g}}$ at a snow density of $350 \mathrm{~kg} \mathrm{~m}^{-3}$ and a mean snow temperature of $-30^{\circ} \mathrm{C}$. The snow density and mean snow temperature were chosen from results of Figures 3 and 5. Figure 7 demonstrates that the increase in snow hardness reaches $198 \mathrm{kPa}$ after 6 hours, if the temperature gradient is $100 \mathrm{~K} \mathrm{~m}^{-1}$. Although the precise value of the temperature gradient in our observations is unknown, radiation cooling occurred after both drifting snow events. In our observations, the bonds between strongly packed snow particles became stronger within a few days of the end of drifting snow events, while radiation cooling led to a strong temperature gradient. As there was no rain during our observations, snow particles with strong bonds after drifting snow events were not due to melting and

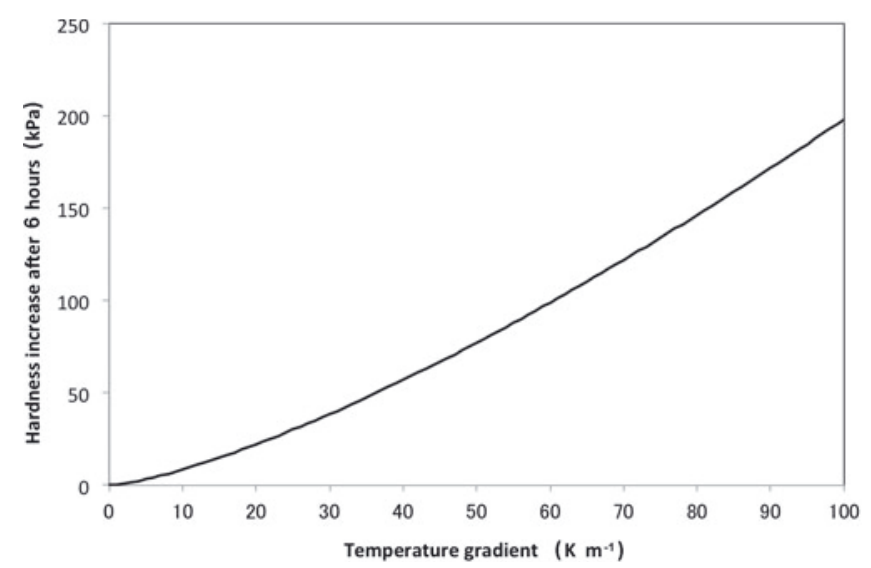

Fig. 7. Relationship between the increase in snow hardness after 6 hours, $\Delta H$, and the temperature gradient, $T_{\mathrm{g}}$. refreezing effects but, rather, to hardening over time during water-vapor transport under a temperature gradient.

Drifting snow develops from the impact of snow particles on the snow surface, and the hard snow surface, where snow particles cannot break the particle bonds, gradually appears as an erosion area. Snow particles with strong bonds after drifting snow events were, thus, also due to exposure of the inner snow layer during drifting snow erosion. The rapid change of snow surface hardness in this study is likely to arise mainly from two different mechanisms: (1) higher density due to wind-packing, which promotes the processes of metamorphism leading to a rapid increase in snow hardness under a strong temperature gradient; and (2) snowdrift causing strong erosion of snow surfaces until the hard inner layers are exposed.

The time-dependent development of snow surface hardness and density differs considerably (Fig. 8). When the snow surface density increased, the surface tended to harden. The values of snow surface hardness during drifting snow events were generally small. The snow surface hardness on 24 February, after the end of a drifting snow event, increased rapidly relative to the increase in snow surface density.

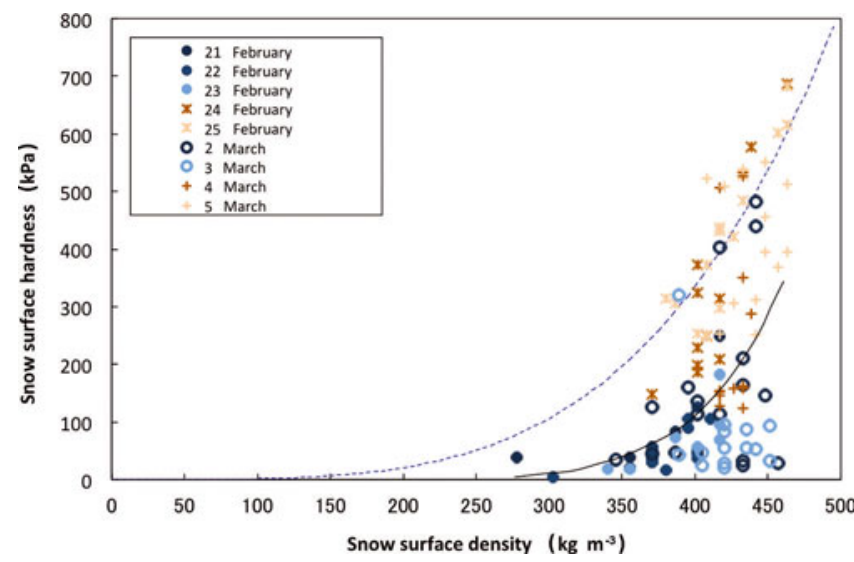

Fig. 8. Relationship between snow surface density, $D$, and snow surface hardness, $H$. The dotted curve was obtained by Takeuchi and others (1998); the solid curve was estimated by the method of least squares using data generated in our study. 
Kinosita (1960) obtained experimental equations describing the hardness and density of compacted snow using a compressing machine, and showed that snow hardness was proportional to the fourth power of the snow density. Figure 8 shows the experimental equation $(H=1.31 \times$ $10^{-8} D^{4}$, where $H$ is the snow surface hardness $(\mathrm{kPa})$ and $D$ is the snow surface density $\left.\left(\mathrm{kg} \mathrm{m}^{-3}\right)\right)$ found by Takeuchi and others (1998) using a push-pull gauge in field-compacted snow with grain sizes $<0.5 \mathrm{~mm}$ and snow temperatures from -3 to $0^{\circ} \mathrm{C}$. This experimental equation also found hardness proportional to the fourth power of the snow density.

Data we obtained at the end of drifting snow events were found to be distributed around the experimental equations. Given that the experimental equation of Takeuchi and others (1998) was based on compacted snow within the snowpack layer, it seemed that bonds between snow particles developed due to the large amount of time. Similarly, because some of our data were generated by exposure of the inner snow layer during drifting snow erosion, the data obtained at the end of drifting snow events were distributed around the above-mentioned experimental equation. The temperature of the snow in this study was lower than that in the experimental equation; accordingly, the snow was expected to be harder. However, because the bonds of the uppermost snow surface layer consisted of impacting, rebounding and ejected snow particles and were not well developed, the hardness of the snow particles during the drifting snow events was softer than that expected from the experimental equation.

The relationship between the snow surface hardness and the snow surface density found in our study can be given as follows:

$$
H=4 \times 10^{-19} D^{7.8} .
$$

The snow surface hardness in this study was proportional to the 7.8th power of the snow density and changed rapidly after the end of drifting snow events.

\section{ACKNOWLEDGEMENTS}

This work was supported by Grant-in-Aid for Scientific Research (C) (22540456). We thank D.J. Endres of the NOAA's Earth and Space Research Laboratory (ESRL)/Global Monitoring Division (GMD) and the Barrow Arctic Science
Consortium (G.W. Sheehan and others) for their help and support. We are grateful for the helpful comments provided by anonymous reviewers.

\section{REFERENCES}

Aburakawa, H., K. Tusima and N. Sato. 1972. Studies of hard snow in Mt. Daisetu II. Low Temp. Sci., Ser. A 30, 129-143. [In Japanese with English summary.]

Akitaya, E. 1985. Quick hardening of snow under a strong temperature gradient. Low Temp. Sci., Ser. A 44, 27-35. [In Japanese with English summary.]

Benson, C.S. and M. Sturm. 1993. Structure and wind transport of seasonal snow on the Arctic slope of Alaska. Ann. Glaciol., 18, 261-267.

Colbeck, S.C. 1987. Theory of particle coarsening with a lognormal distribution. Acta Metall., 35(7), 1583-1588.

Fierz, C. and 8 others. 2009. The international classification for seasonal snow on the ground. Paris, UNESCO-International Hydrologic Programme. (IHP Technical Documents in Hydrology 83.)

Gray, J.M.N.T. and L.W. Morland. 1995. The compaction of polar snow packs. Cold Reg. Sci. Technol., 23(2), 109-119.

Kinosita, S. 1960. The hardness of snow. Low Temp. Sci., Ser. A 19, 119-134. [In Japanese with English summary.]

Kobayashi, T. 1978. The temperature and the density dependences on hardness of artificially compacted snow. Rep. Natl Res. Cent. Disaster Prev. 20, 267-292. [In Japanese with English summary.]

Martinelli, M., Jr. 1971. Physical properties of alpine snow as related to weather and avalanche conditions. USDA Forest Serv. Res. Pap. RM-64.

Sato, T., T. Kimura, T. Ishimaru and T. Maruyama. 1993. Field test of a new snow-particle counter (SPC) system. Ann. Glaciol., 18, 149-154.

Sommerfeld, R.A. and E. LaChapelle. 1970. The classification of snow metamorphism. J. Glaciol., 9(55), 3-17.

Sugiura, K., K. Nishimura, N. Maeno and T. Kimura. 1998. Measurements of snow mass flux and transport rate at different particle diameters in drifting snow. Cold Reg. Sci. Technol., 27(2), 83-89.

Takeuchi, Y., Y. Nohguchi, K. Kawashima and K. Izumi. 1998. Measurement of snow-hardness distribution. Ann. Glaciol., 26, 27-30.

Takeuchi, Y., Y. Nohguchi, K. Kawashima and K. Izumi. 2001. Snow hardness measurement using a digital load gauge. Seppyo, J. Jpn. Soc. Snow Ice, 63(5), 441-449. [In Japanese with English summary.] 